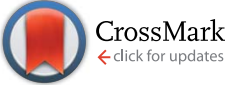

Cite this: RSC Adv., 2017, 7, 3455
Received 11th November 2016 Accepted 28th November 2016

DOI: 10.1039/c6ra26630d

www.rsc.org/advances

\section{Fine silver sulfide-platinum nanocomposites supported on carbon substrates for the methanol oxidation reaction $\uparrow$}

\begin{abstract}
Jiayi Tang, ${ }^{\text {ab }}$ Dong Chen, ${ }^{a}$ Chengyin Li, ${ }^{a}$ Xianfeng Yang, ${ }^{c}$ Hui Liu ${ }^{\star a d}$ and Jun Yang ${ }^{\star a b d}$
Nanocomposites composed of silver sulfide $\left(\mathrm{Ag}_{2} \mathrm{~S}\right)$ and platinum (Pt) metal are promising for electrocatalysis. However, they suffer from low concentration synthesis or larger sizes due to limitations in the current synthetic approaches. Herein, we report an organic synthesis to address these deficiencies for the preparation of $\mathrm{Ag}_{2} \mathrm{~S}-\mathrm{Pt}$ nanocomposites. This strategy starts with a dodecylamine (DDA)-based phase transfer of $\mathrm{Ag}^{+}$ions from the aqueous phase to toluene. The transferred $\mathrm{Ag}^{+}$ions are then loaded on the carbon substrates, followed by reaction with elemental sulfur to form carbon-supported $\mathrm{Ag}_{2} \mathrm{~S}$ nanocrystals, which are used as seeds for the growth of a Pt metal shell, resulting in the formation of the $\mathrm{Ag}_{2} \mathrm{~S}-\mathrm{Pt}$ nanocomposites on the same carbon substrates. The as-prepared carbon-supported $\mathrm{Ag}_{2} \mathrm{~S}-\mathrm{Pt}$ nanocomposites have a core-shell construction with an overall fine size of $c a .5 \mathrm{~nm}$. In comparison with the commercial Pt/C catalysts from Johnson Matthey, fine $\mathrm{Ag}_{2} \mathrm{~S}-\mathrm{Pt}$ nanocomposites supported on the carbon substrates exhibit a superior specific activity and durability for the methanol oxidation reaction under acidic conditions due to the strong electronic coupling effect between the $\mathrm{Ag}_{2} \mathrm{~S}$ and $\mathrm{Pt}$ domains.
\end{abstract}

\section{Introduction}

Nanocomposites composed of silver sulfide $\left(\mathrm{Ag}_{2} \mathrm{~S}\right)$ and platinum (Pt) have been demonstrated in our previous studies as potential candidates in electrocatalysis. ${ }^{1,2}$ The electron transfer from $\mathrm{Ag}_{2} \mathrm{~S}$ to $\mathrm{Pt}$ in the composite material due to the alignment of energy levels leads to a substantial increase in the electron density around the Pt domain, which inhibits the chemisorption of $\mathrm{CO}$ and promotes the methanol oxidation reaction (MOR). ${ }^{3}$ The selectivity of the $\mathrm{Ag}_{2} \mathrm{~S}-\mathrm{Pt}$ nanocomposites for the MOR could even be used to construct a membraneless direct methanol fuel cell (DMFC) by integrating it with a cathode selective catalyst. ${ }^{4}$ The strategies used to prepare $\mathrm{Ag}_{2} \mathrm{~S}-\mathrm{Pt}$ nanocomposites were usually carried out via a solution-based approach either by depositing Pt metal on the $\mathrm{Ag}_{2} \mathrm{~S}$ seeds ${ }^{3}$ or

${ }^{a}$ State Key Laboratory of Multiphase Complex Systems, Institute of Process Engineering, Chinese Academy of Sciences, Beijing, 100190, China. E-mail: jyang@ ipe.ac.cn; yfchen@ipe.ac.cn; Fax: +86-10-8254-4915; +86-10-8254-4919; Tel: +86-108254-4915; +86-10-8254-4896

${ }^{b}$ University of Chinese Academy of Sciences, No. 19A Yuquan Road, Beijing 100049, China

${ }^{c}$ Analytical and Testing Centre, South China University of Technology, Guangzhou 510640, China

${ }^{d}$ Center for Mesoscience, Institute of Process Engineering, Chinese Academy of Sciences, Beijing 100190, China

$\dagger$ Electronic supplementary information (ESI) available: XRD patterns of the carbon-supported $\mathrm{Ag}_{2} \mathrm{~S}$ seeds and $\mathrm{Ag}_{2} \mathrm{~S}-\mathrm{Pt}$ nanocomposites, chronoamperograms and Pt 4f XPS spectra of carbon-supported $\mathrm{Ag}_{2} \mathrm{~S}-\mathrm{Pt}$ nanocomposites and commercial Pt/C catalysts. See DOI: 10.1039/c6ra26630d by a structural conversion process. ${ }^{5,6}$ Unfortunately, the shortcomings of the current synthetic routes are apparent. For the seed-mediated growth, BSPP(bis(p-sulfonatophenyl)phenyl phosphane) was used to direct the synthesis of the $\mathrm{Ag}_{2} \mathrm{~S}$ seeds in the aqueous phase, followed by the reduction of Pt precursors using sodium citrate to form $\mathrm{Ag}_{2} \mathrm{~S}-\mathrm{Pt}$ heterogeneous nanocomposites. However, the expensive nature of BSPP and the aqueous phase entailed that the synthesis could only be performed at very low concentrations. ${ }^{3}$ For the structural conversion, core-shell Ag-Pt nanoparticles were used as precursors to react with the elemental sulfur for the production of nanocomposites consisting of $\mathrm{Ag}_{2} \mathrm{~S}$ and hollow Pt nanostructures. However, the high content of $\mathrm{Ag}$ in the core-shell Ag-Pt precursors makes the formed $\mathrm{Ag}_{2} \mathrm{~S}$-hollow Pt nanocomposites have a very low surface area exposed to the electrochemical reactions. ${ }^{5}$

In this study, we report an organic synthesis to address the abovementioned deficiencies in the standard synthesis of $\mathrm{Ag}_{2} \mathrm{~S}-$ $\mathrm{Pt}$ nanocomposites. The novelty of this work lies in its synthetic approach, which is based on a combination of the phase transfer of $\mathrm{Ag}^{+}$ions with the inhibition of $\mathrm{Ag}_{2} \mathrm{~S}$ growth on the carbon substrates to generate $\mathrm{Ag}_{2} \mathrm{~S}-\mathrm{Pt}$ nanocomposites with fine sizes. This strategy starts with a dodecylamine (DDA)-based phase transfer of $\mathrm{Ag}^{+}$ions from the aqueous phase to a nonpolar organic solvent such as toluene. The transferred $\mathrm{Ag}^{+}$ ions are then loaded on the carbon substrates, followed by reaction with elemental sulfur to form carbon-supported $\mathrm{Ag}_{2} \mathrm{~S}$ nanocrystals $\left(\mathrm{Ag}_{2} \mathrm{~S} / \mathrm{C}\right)$. Finally, the $\mathrm{Ag}_{2} \mathrm{~S}$ nanocrystals are used as seeds for the deposition of Pt metal, resulting in the formation 
of $\mathrm{Ag}_{2} \mathrm{~S}-\mathrm{Pt}$ nanocomposites on the carbon substrates. The microscopic analyses indicate that the as-prepared carbonsupported $\mathrm{Ag}_{2} \mathrm{~S}-\mathrm{Pt}$ nanocomposites $\left(\mathrm{Ag}_{2} \mathrm{~S}-\mathrm{PtNCs} / \mathrm{C}\right)$ are fine in size and have a core-shell construction. We demonstrated that the $\mathrm{Ag}_{2} \mathrm{~S}-\mathrm{PtNCs} / \mathrm{C}$ display a superior specific activity and durability in the MOR under acidic conditions. The overall fine sizes and thin Pt shell thickness, which are essential for a high specific surface area and for making the use of electronic coupling effect between the $\mathrm{Ag}_{2} \mathrm{~S}$ and Pt domains, may account for the enhanced catalytic performance of the $\mathrm{Ag}_{2} \mathrm{~S}-\mathrm{PtNCs} / \mathrm{C}$ in the MOR. This concept may shed some light on the production of cost-effective and efficient electrocatalysts on a large scale.

\section{Experimental}

\subsection{Reagents and material}

Potassium tetrachloroplatinate(II) $\left(\mathrm{K}_{2} \mathrm{PtCl}_{4}, 98 \%\right)$, silver nitrate $\left(\mathrm{AgNO}_{3}, 99 \%\right)$, acetic acid $\left(\mathrm{CH}_{3} \mathrm{COOH}, 98 \%\right)$, aqueous $\mathrm{HClO}_{4}$ solution (70\%, ACS reagent), and Nafion 117 solution (5\% in a mixture of lower aliphatic alcohols and water) from Aladdin Reagents; ethanol (99.5\%), methanol (99\%), and toluene (99.5\%) from Beijing Chemical Works; elemental sulfur powder (S, chemical grade) from Xilong Chemical Co. Ltd.; oleylamine (70\%, technical grade) from Sigma-Aldrich; dodecylamine (DDA, chemical grade) from Sinopharm Chemical Co. Ltd.; and Vulcan XC-72 carbon powder (XC-72C) with a BET surface area of $c a .250 \mathrm{~m}^{2} \mathrm{~g}^{-1}$ and an average particle size of $c a .40 \mathrm{~nm}$ from Cabot, were used as received. All glassware and Teflon-coated magnetic stirring bars were cleaned with aqua regia, followed by copious rinsing with deionized water before drying in an oven.

\subsection{Synthesis of the fine carbon-supported $\mathrm{Ag}_{2} \mathrm{~S}$ nanocrystals $\left(\mathrm{Ag}_{2} \mathrm{~S} / \mathrm{C}\right)$}

A DDA-based phase transfer method was used to synthesize the carbon-supported $\mathrm{Ag}_{2} \mathrm{~S}$ nanocrystals with fine sizes. Typically, $50 \mathrm{~mL}$ of aqueous $\mathrm{AgNO}_{3}$ solution $(2 \mathrm{mM}$ ) was mixed with $50 \mathrm{~mL}$ of ethanol containing $1 \mathrm{~mL}$ of DDA for the formation of DDA$\mathrm{Ag}^{+}$complexes. ${ }^{7,8}$ After $3 \mathrm{~min}$ of stirring, $50 \mathrm{~mL}$ of toluene was added and stirred for another $1 \mathrm{~min}$. Subsequently, the upper toluene layer was collected, and a measured amount of XC-72C was added to it. The mixture was then stirred for $6 \mathrm{~h}$ to make $\mathrm{Ag}^{+}$ ions fully adsorb on the carbon substrate. Separately, a sulfur solution was prepared by dissolving $0.5 \mathrm{mmol}$ of sulfur into 10 $\mathrm{mL}$ of toluene, which was then added to the as-prepared $\mathrm{Ag}^{+} / \mathrm{C}$ mixture (the molar ratio of $\mathrm{Ag} / \mathrm{S}$ was set at $1 / 5$ ). Further stirring for $12 \mathrm{~h}$ at room temperature was required for the formation of the carbon-supported $\mathrm{Ag}_{2} \mathrm{~S}$ nanocrystals $\left(\mathrm{Ag}_{2} \mathrm{~S} / \mathrm{C}\right.$ with 5 , 10, or $20 \mathrm{wt} \% \mathrm{Ag}_{2} \mathrm{~S}$ on the carbon support). Once the reaction was finished, the $\mathrm{Ag}_{2} \mathrm{~S} / \mathrm{C}$ nanocrystals were collected by centrifugation and subsequently washed thrice with toluene.

\subsection{Synthesis of fine carbon-supported $\mathrm{Ag}_{2} \mathrm{~S}-\mathrm{Pt}$ nanocomposites $\left(\mathrm{Ag}_{2} \mathrm{~S}-\mathrm{PtNCs} / \mathrm{C}\right)$}

For the preparation of $\mathrm{Ag}_{2} \mathrm{~S}-\mathrm{PtNCs} / \mathrm{C}$, the as-prepared $\mathrm{Ag}_{2} \mathrm{~S} / \mathrm{C}$ (10 $\mathrm{wt} \% \mathrm{Ag}_{2} \mathrm{~S}$ on the carbon support) was redispersed in a 20
$\mathrm{mL}$ of oleylamine in a three-necked flask fitted with a condenser and a stirring bar. The solution was heated to $110{ }^{\circ} \mathrm{C}$, and then $0.05 \mathrm{mmol}$ of $\mathrm{K}_{2} \mathrm{PtCl}_{4}$ was added to the mixture under vigorous stirring. The resulting reaction system was kept at $110^{\circ} \mathrm{C}$ for $2 \mathrm{~h}$ so as to allow the reduction of $\mathrm{Pt}^{2+}$ ions by oleylamine on the surface of the fine $\mathrm{Ag}_{2} \mathrm{~S}$ nanocrystals. The as-obtained $\mathrm{Ag}_{2} \mathrm{~S}-$ $\mathrm{PtNCs} / \mathrm{C}$ were collected by centrifugation, washed thrice with methanol, and then dried in vacuum at room temperature for further characterizations and electrochemical measurements.

\subsection{Sample characterizations}

Transmission electron microscopy (TEM) and high-resolution TEM (HRTEM) were performed using a JEOL JEM-2100F electron microscope operating at $200 \mathrm{kV}$ with supplied software for an automated electron tomography. An energy dispersive X-ray spectroscopy (EDX) analyzer attached to a FEI Tecnai $G^{2}$ F20 electron microscope operating in the scanning STEM mode was used to determine the structure of the $\mathrm{Ag}_{2} \mathrm{~S}-\mathrm{Pt}$ composite nanomaterials. The samples for TEM, HRTEM, and STEM characterizations were prepared by dispensing a drop of the nanocrystal solution onto a $3 \mathrm{~mm}$ carbon-coated copper grid. Excess solution was removed by an absorbent paper, and the samples were dried in air at room temperature. The average particle diameter and the standard deviations were calculated from a few randomly chosen areas in the TEM image containing 100 nanoparticles each. Powder X-ray diffraction (XRD) measurements were carried out using a Bruker D8 focus X-ray diffractometer under $\mathrm{Cu}-\mathrm{K}_{\alpha}$ radiation $(\lambda=1.5406 \AA ̊)$. X-ray photoelectron spectroscopy (XPS) analysis was conducted using a VG ESCALAB MKII spectrometer. Samples employed for the XRD and XPS analyses were $\mathrm{Ag}_{2} \mathrm{~S} / \mathrm{C}$ nanocrystals and $\mathrm{Ag}_{2} \mathrm{~S}-$ $\mathrm{PtNCs} / \mathrm{C}$ collected by centrifugation from their reaction mixtures, which were washed thrice with methanol and dried in vacuum at room temperature.

\subsection{Electrochemical measurements of the $\mathrm{Ag}_{2} \mathrm{~S}-\mathrm{PtNCs} / \mathrm{C}$ - catalyzed MOR}

Electrochemical measurements were carried out in a standard three-electrode cell connected to a Bio-logic VMP3 (with EC-lab software version 9.56) potentiostat. A leak-free $\mathrm{Ag} / \mathrm{AgCl}$ electrode (saturated with $\mathrm{KCl}$ ) was used as the reference electrode. The counter electrode was a platinum mesh $\left(1 \times 1 \mathrm{~cm}^{2}\right)$ attached to a platinum wire.

For the evaluation of the catalytic activity in the MOR, the $\mathrm{Ag}_{2} \mathrm{~S}-\mathrm{PtNCs} / \mathrm{C}$ were first refluxed in acetic acid at $120{ }^{\circ} \mathrm{C}$ for $3 \mathrm{~h}$ to remove the surface coatings, ${ }^{9}$ and then $10 \mathrm{mg}$ of the asprepared $\mathrm{Ag}_{2} \mathrm{~S}-\mathrm{PtNCs} / \mathrm{C}$ (8 $\mathrm{wt} \%$ Pt on the carbon support) was dispersed into $10 \mathrm{~mL}$ of aqueous solution containing $4 \mathrm{~mL}$ of ethanol and $0.1 \mathrm{~mL}$ of Nafion solution. A calculated volume of the as-obtained catalyst ink was dispensed onto a $5 \mathrm{~mm}$ glassy carbon disk electrode to produce a nominal catalyst loading of 8 $\mu \mathrm{g} \mathrm{cm}{ }^{-2}$ (based on the Pt content). The carbon electrode was then dried in a stream of warm air at $70{ }^{\circ} \mathrm{C}$ for $1 \mathrm{~h}$.

The cyclic voltammograms of $\mathrm{Ag}_{2} \mathrm{~S}-\mathrm{PtNCs} / \mathrm{C}$ and commercial $\mathrm{Pt} / \mathrm{C}$ catalysts were obtained in an argon-purged $\mathrm{HClO}_{4}(0.1 \mathrm{M})$ at room temperature to determine the electrochemically active 
surface areas (ECSAs) of Pt. The catalyst performance in the MOR was also evaluated by cyclic voltammetry in an electrolyte (1 M methanol in $0.1 \mathrm{M}$ perchloric acid) within a potential window of $-0.2 \mathrm{~V}$ to $1 \mathrm{~V}$ at a scanning rate of $20 \mathrm{mV} \mathrm{s}^{-1}$. The current densities for the tested catalysts were normalized by their ECSAs to obtain the specific activities.

\section{Results and discussion}

In this study, we aimed at making use of the substrates to inhibit the growth of $\mathrm{Ag}_{2} \mathrm{~S}$ nanocrystals for the preparation of $\mathrm{Ag}_{2} \mathrm{~S}-\mathrm{Pt}$ nanocomposites with fine sizes. The overall strategy for the synthesis of $\mathrm{Ag}_{2} \mathrm{~S}-\mathrm{Pt}$ nanocomposites with fine sizes on the surface of carbon substrates is summarized in Fig. 1. It was confirmed using ICP-AES (inductively coupled plasma atomic emission spectroscopy) analysis that the loading efficiency of $\mathrm{Ag}^{+}$ions on the XC-72C carbon support from the organic medium (ca. 100\%) is much higher than that from the aqueous phase (ca. 35\%); therefore, before loading on the surface of the carbon substrates, $\mathrm{Ag}^{+}$ions were first transferred to toluene via a process mediated by ethanol and dodecylamine. ${ }^{7,8}$ Then, upon mixing with elemental sulfur in toluene, $\mathrm{Ag}^{+}$ions were converted into the $\mathrm{Ag}_{2} \mathrm{~S}$ nanocrystals on the surface of the carbon support. The as-prepared carbon-supported $\mathrm{Ag}_{2} \mathrm{~S}$ nanocrystals were subsequently used as seeds for the growth of a Pt metal shell in oleylamine, as indicated by the last step in Fig. 1.

The successful synthesis of $\mathrm{Ag}_{2} \mathrm{~S}$ nanocrystals on the surface of carbon substrates was confirmed by the powder X-ray diffraction (XRD) pattern, as shown in Fig. S1b in the ESI. $\dagger$ This XRD image for the $\mathrm{Ag}_{2} \mathrm{~S} / \mathrm{C}$ sample with a $\mathrm{Ag}_{2} \mathrm{~S} / \mathrm{C}$ mass ratio of $10 \%$ demonstrates that the as-prepared $\mathrm{Ag}_{2} \mathrm{~S}$ nanocrystals have a monoclinic phase (ESI Fig. S1a † for the $\mathrm{Ag}_{2} \mathrm{~S}$ reference with JCPDS card no. 140072). Fig. 2 shows the TEM images of the $\mathrm{Ag}_{2} \mathrm{~S}$ nanocrystals supported on carbon with a $\mathrm{Ag}_{2} \mathrm{~S} / \mathrm{C}$ mass ratio of $20 \%$ (Fig. 2a), $10 \%$ (Fig. 2c), and 5\% (Fig. 2e), which are spherical, monodispersed, and uniformly dispersed on the carbon substrates. The boundaries between the $\mathrm{Ag}_{2} \mathrm{~S}$ particles and the carbon substrates could be clearly discerned from the

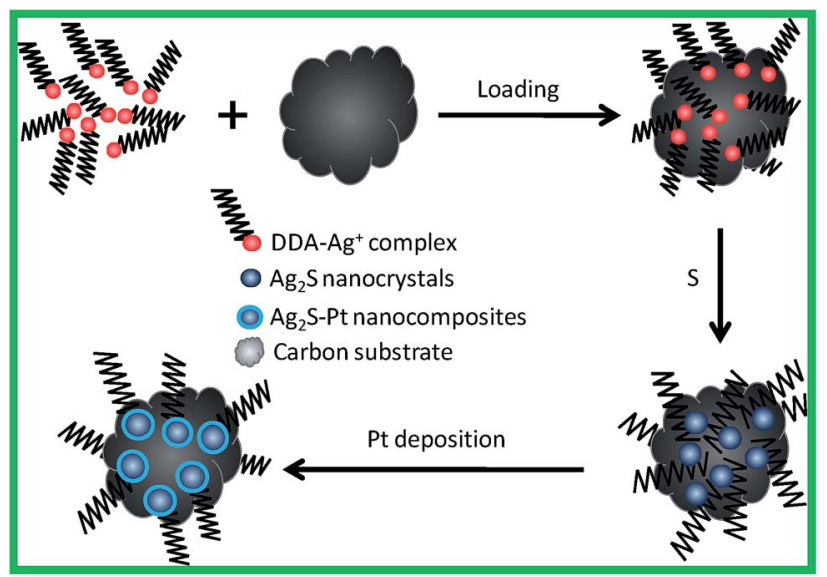

Fig. 1 Schematic for the synthesis of $\mathrm{Ag}_{2} \mathrm{~S}-\mathrm{Pt}$ nanocomposites with fine sizes on the surface of carbon substrates.
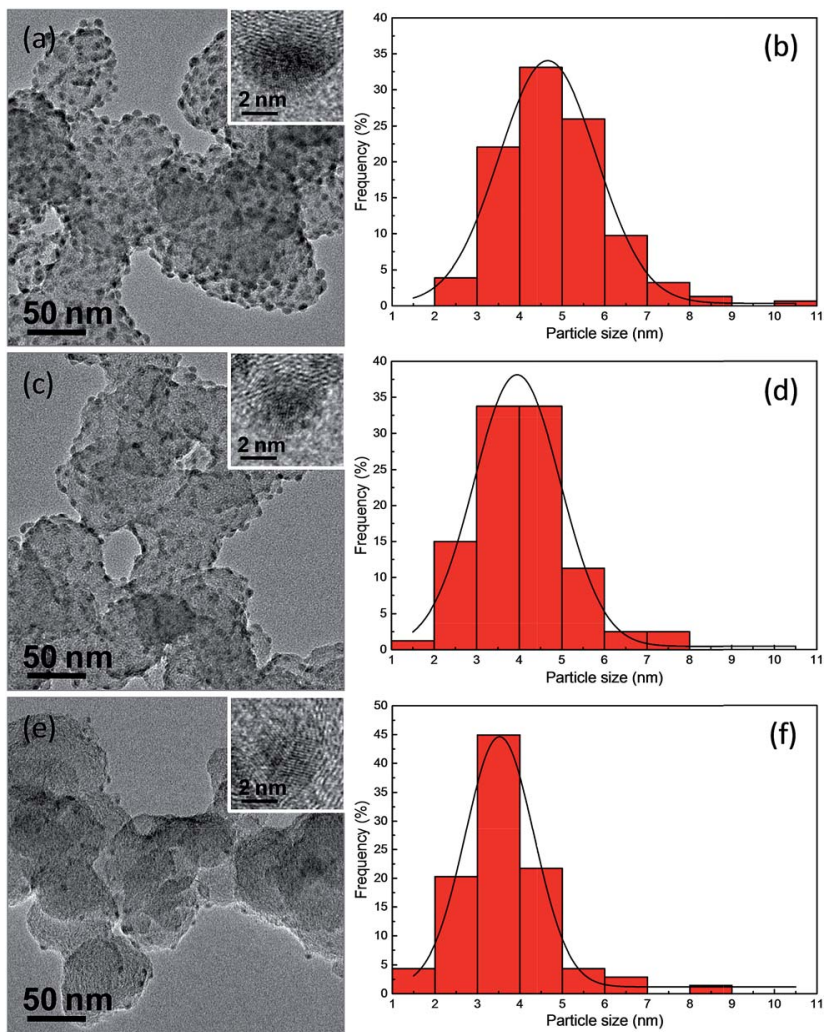

Fig. 2 TEM images ( $a, c$, and e) and histograms with the size distributions (b, d, and f) of $\mathrm{Ag}_{2} \mathrm{~S}$ particles supported on carbon with a $\mathrm{Ag}_{2} \mathrm{~S} /$ C mass ratio of $20 \%$ ( $a$ and $b$ ), $10 \%$ (c and $d$ ), and $5 \%$ (e and $f$ ).

brightness contrast. The HRTEM images (inset in each TEM image) illustrate the lattice planes in these $\mathrm{Ag}_{2} \mathrm{~S} / \mathrm{C}$ nanocrystals, confirming their high crystallinity. Moreover, as indicated by the corresponding particle size distributions (Fig. 2b, d and f), the average sizes for the carbon-supported $\mathrm{Ag}_{2} \mathrm{~S}$ nanocrystals are $4.85 \mathrm{~nm}$ with a standard deviation of $0.10 \mathrm{~nm}$ for the nanocrystals with a $\mathrm{Ag}_{2} \mathrm{~S} / \mathrm{C}$ mass ratio of $20 \%, 4.03 \mathrm{~nm}$ with a standard deviation of $0.12 \mathrm{~nm}$ for the nanocrystals with a $\mathrm{Ag}_{2} \mathrm{~S} / \mathrm{C}$ mass ratio of $10 \%$, and $3.69 \mathrm{~nm}$ with a standard deviation of $0.14 \mathrm{~nm}$ for the nanocrystals with a $\mathrm{Ag}_{2} \mathrm{~S} / \mathrm{C}$ mass ratio of $5 \%$. As expected, the average diameter of the $\mathrm{Ag}_{2} \mathrm{~S}$ nanocrystals on the surface of carbon substrates is much smaller than that obtained in the aqueous phase by using BSPP$\mathrm{Ag}^{+}$complexes as precursors $(7.2 \mathrm{~nm})^{3}$ or that obtained from the thiol-stabilized Ag clusters in an organic medium $(16 \mathrm{~nm}){ }^{{ }^{10}}$

We chose $\mathrm{Ag}_{2} \mathrm{~S} / \mathrm{C}$ nanocrystals with a $\mathrm{Ag}_{2} \mathrm{~S} / \mathrm{C}$ mass ratio of $10 \%$ as seeds for the preparation of carbon-supported $\mathrm{Ag}_{2} \mathrm{~S}-\mathrm{Pt}$ nanocomposites $\left(\mathrm{Ag}_{2} \mathrm{~S}-\mathrm{PtNCs} / \mathrm{C}\right)$. As indicated in the TEM image (Fig. 3a) of the as-prepared $\mathrm{Ag}_{2} \mathrm{~S}-\mathrm{PtNCs} / \mathrm{C}$, the average diameter of the $\mathrm{Ag}_{2} \mathrm{~S}$ nanocrystals on the surface of carbon substrates is increased from $4.03 \mathrm{~nm}$ to $5.04 \mathrm{~nm}$ after the deposition of Pt. This increase in the particle size might be attributable to the formation of the Pt shell with a thickness of $0.5 \mathrm{~nm}$, which corresponds to 1-2 layers of Pt. Since the semiconductor nanocrystals have a catalytic capability for the reduction of metal ion precursors (in this case, $\mathrm{Ag}_{2} \mathrm{~S}$ and $\mathrm{Pt}$ ions), ${ }^{7,11,12}$ the isolated Pt deposition on the XC-72 carbon 

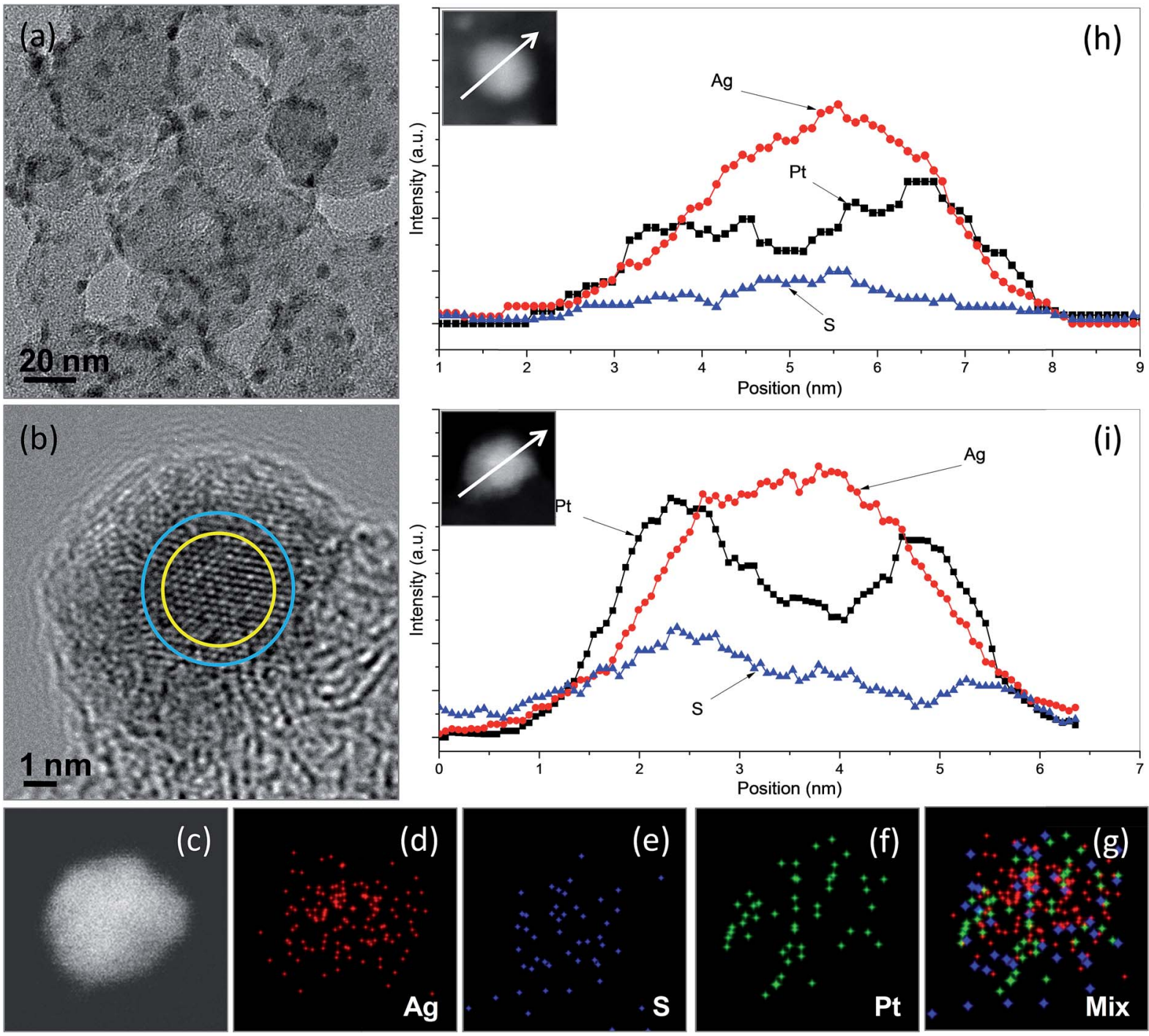

Fig. 3 TEM image (a), HRTEM image (b), nanoscale element mappings (c-g), and elemental profiles in STEM mode (h and i) of $A g_{2} S-P t$ nanocomposites supported in carbon substrates prepared in oleylamine at elevated temperature using $\mathrm{Ag}_{2} \mathrm{~S} / \mathrm{C}$ with mass ratio of $10 \%$ as seeds. Insets in (h) and (i) are the corresponding composite particles to obtain the Ag, S, and Pt elemental profiles.

substrate is less favourable. In the TEM images, the nanocomposites constructed with semiconductors and noble metals usually have apparent brightness contrasts between the semiconductor and metal domains due to the difference in the electron densities. ${ }^{3,5,13-19}$ In this study, although we did not succeed to observe the brightness contrasts between the $\mathrm{Ag}_{2} \mathrm{~S}$ and $\mathrm{Pt}$ domains in the $\mathrm{Ag}_{2} \mathrm{~S}-\mathrm{Pt}$ nanocomposites due to their fine particle sizes and the influence of the carbon background, a successful synthesis of the $\mathrm{Ag}_{2} \mathrm{~S}-\mathrm{Pt}$ nanocomposites as well as their structural features could be inferred by the HRTEM image and the EDX-based line scanning and mapping analyses in the STEM mode. Fig. $3 \mathrm{~b}$ shows the HRTEM image of a single $\mathrm{Ag}_{2} \mathrm{~S}-$ Pt composite particle on the carbon substrates, in which the lattice difference between the peripheral and central regions indicates that the growth of Pt uniformly occurred on the $\mathrm{Ag}_{2} \mathrm{~S}$ seed, leading to the formation of $\mathrm{Ag}_{2} \mathrm{~S}-\mathrm{Pt}$ nanocomposites with a core-shell construction. The distributions of $\mathrm{Pt}, \mathrm{Ag}$, and $\mathrm{S}$ elements in an arbitrary single particle, which were analyzed by
EDX under the high-angle annular dark-field scanning TEM (HAADF-STEM) mode, were also used to confirm the core-shell structure of the $\mathrm{Ag}_{2} \mathrm{~S}-\mathrm{Pt}$ nanocomposites. Nanoscale elemental mapping images (Fig. $3 \mathrm{c}-\mathrm{g}$ ) revealed that $\mathrm{Ag}$ and $\mathrm{S}$ in the composite particles are concentrated in the core region, whereas Pt is distributed throughout the entire particle, clearly suggesting the formation of a $\mathrm{Ag}_{2} \mathrm{~S}-\mathrm{Pt}$ core-shell structure. Mapping analyses are fairly consistent with the element profiles of two arbitrary single $\mathrm{Ag}_{2} \mathrm{~S}-\mathrm{Pt}$ particles (Fig. $3 \mathrm{~h}$ and i), which also support that the $\mathrm{Ag}_{2} \mathrm{~S}-\mathrm{Pt}$ nanocomposites formed on the carbon substrates by seed-mediated growth have a core-shell structure. The XRD pattern of the as-prepared $\mathrm{Ag}_{2} \mathrm{~S}-\mathrm{PtNCs} / \mathrm{C}$ was analyzed, as shown in Fig. S1c in the ESI. $\dagger$ Note that although the HRTEM image and STEM-based scanning and mapping analyses in Fig. 3 collectively illustrate the formation of core-shell $\mathrm{Ag}_{2} \mathrm{~S}$-Pt nanocomposites on the surface of carbon substrates, the diffraction peaks from $\mathrm{Pt}$ metal are hardly detectable (as evinced by Fig. S1d in the ESI $\dagger$ for the Pt reference 
with JCPDS card no. 882343). The diffraction peaks in Fig. S1c (in the ESI $\dagger$ ) also show the feature of a monoclinic $\mathrm{Ag}_{2} \mathrm{~S}$ phase. Hence, it could be supposed that the interplanar spacing of $\mathrm{Pt}$ changes to match the lattice distances in $\mathrm{Ag}_{2} \mathrm{~S}$ for its epitaxial growth on the surface of $\mathrm{Ag}_{2} \mathrm{~S}$ seeds, analogous to that occurred in the core-shell CdSe-Pt hybrid systems. ${ }^{20}$ In addition, although Pt atoms, reduced from their precursors, preferentially nucleate on the existing fine $\mathrm{Ag}_{2} \mathrm{~S}$ nanocrystals rather than on the carbon substrates, the final composite products are quite different from the $\mathrm{Ag}_{2} \mathrm{~S}-\mathrm{Pt}$ nanocomposites synthesized in the aqueous phase, in which the Pt dots instead of continuous Pt shells are decorated on the multiple sites of the surface of the $7.2 \mathrm{~nm} \mathrm{Ag}_{2} \mathrm{~S}$ nanocrystals. ${ }^{3}$

We examined the performance of $\mathrm{Ag}_{2} \mathrm{~S}-\mathrm{PtNCs} / \mathrm{C}$ for catalyzing the methanol oxidation reaction (MOR) at room temperature and benchmarked it against that of the commercial Pt/C catalysts from Johnson Matthey (JM). As shown in Fig. 4a, cyclic voltammetry was used to determine the electrochemically active surface areas (ECSAs) of the $\mathrm{Ag}_{2} \mathrm{~S}-\mathrm{PtNCs} / \mathrm{C}$ as well as the commercial Pt/C catalysts. The specific ECSAs, based on the unit weight of $\mathrm{Pt}$ and calculated by integrating the charge associated with the hydrogen adsorption/desorption potential region after double-layer correction, are $44.5 \mathrm{~m}^{2} \mathrm{~g}^{-1}$ for $\mathrm{Ag}_{2} \mathrm{~S}-$ PtNCs/C and $73.8 \mathrm{~m}^{2} \mathrm{~g}^{-1}$ for the commercial Pt/C catalysts, respectively. The lower ECSA of the core-shell $\mathrm{Ag}_{2} \mathrm{~S}-\mathrm{Pt}$
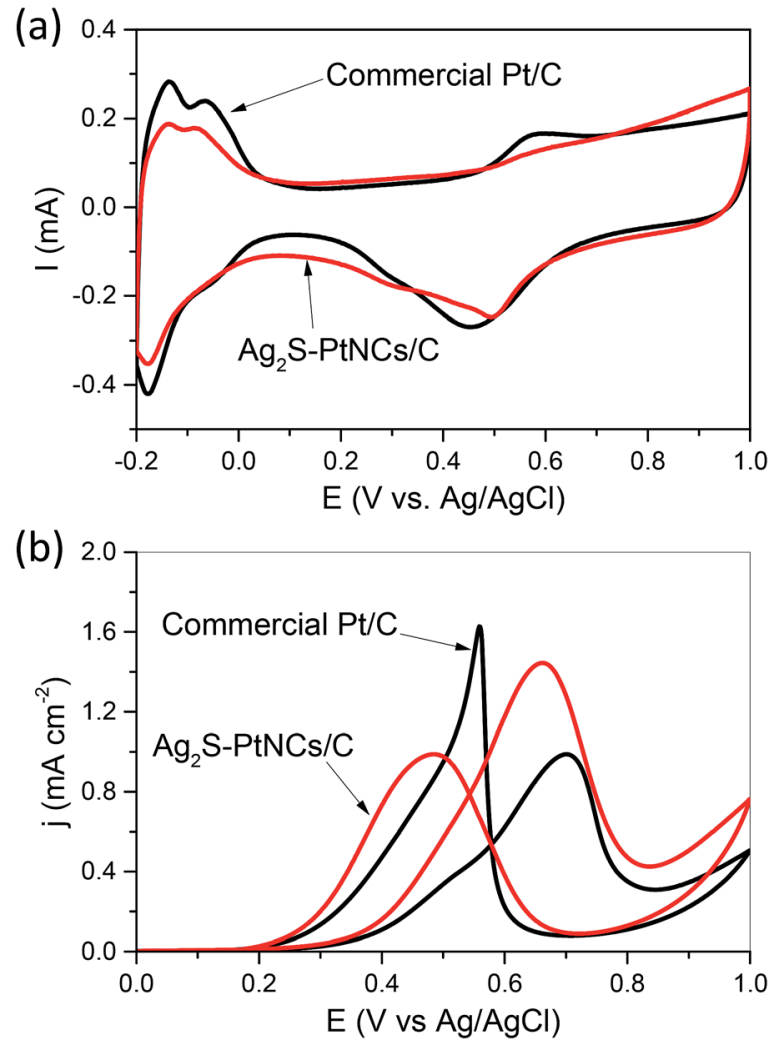

Fig. 4 Cyclic voltammograms of the $\mathrm{Ag}_{2} \mathrm{~S}-\mathrm{PtNCs} / \mathrm{C}$ and commercial $\mathrm{Pt} / \mathrm{C}$ catalysts in an argon-purged $0.1 \mathrm{M} \mathrm{HClO}_{4}$ electrolyte at a scan rate of $50 \mathrm{mV} \mathrm{s}^{-1}$ (a); cyclic voltammograms of the $\mathrm{Ag}_{2} \mathrm{~S}-\mathrm{PtNCs} / \mathrm{C}$ and commercial Pt/C catalysts in an argon-purged $0.1 \mathrm{M} \mathrm{HClO}_{4}$ electrolyte with $1 \mathrm{M}$ methanol at a scan rate of $20 \mathrm{mV} \mathrm{s}^{-1}(\mathrm{~b})$. nanocomposites are most likely due to the presence of residual impurities, e.g. residual DDA, amides originated from the oxidation of oleylamine ligands, ${ }^{21}$ and excess sulfur, adsorbed on the surface and their slightly larger sizes compared to those of Pt nanoparticles (ca. $3 \mathrm{~nm}$ ) in the commercial catalysts.

Fig. 4b shows the cyclic voltammograms obtained for the MOR within a potential window of $0-1 \mathrm{~V}$ at a scan rate of $20 \mathrm{mV}$ $\mathrm{S}^{-1}$, in which the current densities are normalized to the ECSA of Pt. As indicated, $\mathrm{Ag}_{2} \mathrm{~S}-\mathrm{PtNCs} / \mathrm{C}$ display a superior activity in the MOR due to the electronic coupling effect between the $\mathrm{Ag}_{2} \mathrm{~S}$ and Pt domains. ${ }^{3,4,6}$ In detail, the peak current density associated with the methanol oxidation in the forward scan, which is an important parameter while evaluating the catalytic activity, ${ }^{22,23}$ is 1.45 $\mathrm{mA} \mathrm{cm}{ }^{-2}$, which is much higher than that of the commercial $\mathrm{Pt} / \mathrm{C}$ catalysts $\left(0.99 \mathrm{~mA} \mathrm{~cm}^{-2}\right)$. It should be emphasized that the ECSAbased specific activities indicate the intrinsic catalytic performance of Pt in different chemical environments. If the calculations were based on the geometric area $\left(0.196 \mathrm{~cm}^{2}\right)$ of the glassy carbon electrode, the current densities in the forward scan in the MOR for the $\mathrm{Ag}_{2} \mathrm{~S}-\mathrm{PtNCs} / \mathrm{C}$ and commercial Pt/C catalysts are comparable, as shown in Fig. S4 in the ESI. $\dagger$ Moreover, the onset potential in the MOR (crosspoint between the $E$-axis and the linear segment of the cyclic voltammograms) is $c a .0 .29 \mathrm{~V}$ for $\mathrm{Ag}_{2} \mathrm{~S}-\mathrm{PtNCs} / \mathrm{C}$, which is lower than that of the commercial Pt/C catalyst ( $c a .0 .32 \mathrm{~V}$ ), indicating that the oxidation of methanol is easier on $\mathrm{Ag}_{2} \mathrm{~S}-\mathrm{Pt} \mathrm{NCs} / \mathrm{C}$ than that on the commercial $\mathrm{Pt} / \mathrm{C}$ catalysts. In particular, the higher $I_{\mathrm{f}} / I_{\mathrm{b}}$ (in which $I_{\mathrm{f}}$ and $I_{\mathrm{b}}$ are the forward and backward current densities, respectively) ratio as compared to that of the commercial Pt/C catalyst (1.45 vs. 0.61) indicates the higher durability of $\mathrm{Ag}_{2} \mathrm{~S}-\mathrm{PtNCs} / \mathrm{C}$ for the methanol oxidation, ${ }^{\mathbf{2 4 , 2 5}}$ which could be confirmed by the chronoamperometric (CA) tests. As shown in Fig. S2 in the ESI, $\uparrow$ the chronoamperograms show that the current density of $\mathrm{Ag}_{2} \mathrm{~S}-\mathrm{PtNCs} / \mathrm{C}$ is higher than that of the commercial $\mathrm{Pt} / \mathrm{C}$ for the entire time course, verifying that $\mathrm{Ag}_{2} \mathrm{~S}-\mathrm{PtNCs} / \mathrm{C}$ exhibit a better electrocatalytic performance in the MOR.

The electronic coupling effect could be qualitatively illustrated by analyzing the binding energies of the $\mathrm{Pt} 4 \mathrm{f}$ region in the $\mathrm{Ag}_{2} \mathrm{~S}-\mathrm{PtNCs} / \mathrm{C}$ and commercial Pt/C catalysts. As displayed in Fig. S3 in the ESI, $\dagger$ while comparing with the binding energies of $\mathrm{Pt} 4 \mathrm{f}$ for commercial Pt/C catalysts, a shift to lower values is observed for $\mathrm{Ag}_{2} \mathrm{~S}-\mathrm{PtNC} / \mathrm{C}$, indicating that there is an electron transfer or drift from the $\mathrm{Ag}_{2} \mathrm{~S}$ core to the Pt shell in the nanocomposites. Analogous to the electron donation from Sn to Pt in the bimetallic Pt-Sn system and in other composite systems combining dielectric property with thermal conductivity, ${ }^{26-28}$ the electron transfer/drift from $\mathrm{Ag}_{2} \mathrm{~S}$ to Pt can lead to a substantial increase in the electron density around the Pt atoms, which is favorable for weakening the chemisorption of CO-like intermediates, produced during methanol oxidation, on the Pt atoms, hence promoting the MOR by preventing the Pt surface from $\mathrm{CO}$ poisoning.

\section{Conclusions}

In summary, we demonstrated an organic-based synthesis of the carbon-supported $\mathrm{Ag}_{2} \mathrm{~S}-\mathrm{Pt}$ nanocomposites with fine sizes 
by combining the phase transfer of $\mathrm{Ag}^{+}$ions with oleylamine reduction of the $\mathrm{Pt}$ metal precursors. The $\mathrm{Ag}_{2} \mathrm{~S}-\mathrm{Pt}$ nanocomposites prepared on the surface of carbon substrates had a core-shell structure, with the thickness of the Pt shell being ca. $0.5 \mathrm{~nm}$, corresponding to the 1-2 Pt atomic layers. The fine carbon-supported $\mathrm{Ag}_{2} \mathrm{~S}-\mathrm{Pt}$ nanocomposites exhibited a superior activity and durability in the methanol oxidation reaction under acidic conditions due to the strong electronic coupling between the $\mathrm{Ag}_{2} \mathrm{~S}$ and Pt domains. By optimizing the overall particle size and the Pt shell thickness of the nanocomposites, we may further improve the catalytic activity of the carbon-supported $\mathrm{Ag}_{2} \mathrm{~S}-\mathrm{Pt}$ nanocomposites in the methanol oxidation. In addition, the strategy used in this work might be extended for the generation of other semiconductor, e.g. $\mathrm{CdS}$ and $\mathrm{PbS}$, or composite nanosystems, e.g. CdS-Pt and PbS-Pt, with fine sizes for electrocatalytic applications.

\section{Acknowledgements}

Financial supports from the National Natural Science Foundation of China (Grant No. 21376247, 21506225, 21573240), the Center for Mesoscience, the Institute of Process Engineering, the Chinese Academy of Sciences (COM2015A001), the New Faculty Start-up funding in South China University of Technology, and the Fundamental Research Funds for the Central Universities are gratefully acknowledged.

\section{Notes and references}

1 H. Liu, Y. Feng, D. Chen, C. Li, P. Cui and J. Yang, J. Mater. Chem. A, 2015, 3, 3182.

2 J. Qu, F. Ye, D. Chen, Y. Feng, Q. Yao, H. Liu, J. Xie and J. Yang, Adv. Colloid Interface Sci., 2016, 230, 29.

3 J. Yang and J. Y. Ying, Angew. Chem., Int. Ed., 2011, 50, 4637. 4 Y. Feng, J. H. Yang, H. Liu, F. Ye and J. Yang, Sci. Rep., 2014, 4, 3813.

5 H. Liu, F. Ye, H. Cao, G. Ji, J. Y. Lee and J. Yang, Nanoscale, 2013, 5, 6901.

6 Y. Feng, H. Liu, P. Wang, F. Ye, Q. Tan and J. Yang, Sci. Rep., 2014, 4, 6204.

7 J. Yang, E. H. Sargent, S. O. Kelley and J. Y. Ying, Nat. Mater., 2009, 8, 683.

8 J. Yang, J. Y. Lee and J. Y. Ying, Chem. Soc. Rev., 2011, 40, 1672.
9 Y. Feng, J. Pan, H. Liu and J. Yang, Particuology, 2016, DOI: 10.1016/j.partic.2016.04.003.

10 Y. Feng, Q. Yao, J. Li, N. Goswami, J. Xie and J. Yang, Nano Res., 2016, 9, 942.

11 J. Yang, H. I. Elim, Q. Zhang, J. Y. Lee and W. Ji, J. Am. Chem. Soc., 2006, 128, 11921.

12 W. Hu, H. Liu, F. Ye, Y. Ding and J. Yang, CrystEngComm, 2012, 14, 7049.

13 T. Mokari, E. Rothenberg, I. Popov, R. Costi and U. Banin, Science, 2004, 304, 1787.

14 T. Mokari, C. G. Sztrum, A. Salant, E. Rabani and U. Banin, Nat. Mater., 2005, 4, 855.

15 G. Menagen, D. Mocatta, A. Salant, I. Popov, D. Dorfs and U. Banin, Chem. Mater., 2008, 20, 6900.

16 M. Li, X. F. Yu, S. Liang, X. N. Peng, Z. J. Yang, Y. L. Wang and Q. Q. Wang, Adv. Funct. Mater., 2011, 21, 1788.

17 N. E. Motl, J. F. Bondi and R. E. Schaak, Chem. Mater., 2012, 24, 1552.

18 D. Wang, X. Li, H. Li, L. Li, X. Hong, Q. Peng and Y. Li, J. Mater. Chem. A, 2013, 1, 1587.

19 K. Vinokurov, Y. Bekenstein, V. Gutkin, I. Popov, O. Millo and U. Banin, CrystEngComm, 2014, 16, 9506.

20 J. H. Yang, X. Chen, F. Ye, C. Wang, Y. Zheng and J. Yang, J. Mater. Chem., 2011, 21, 9088.

21 X. Liu, M. Atwater, J. Wang, Q. Dai, J. Zou, J. P. Brennan and Q. Huo, J. Nanosci. Nanotechnol., 2007, 7, 3126.

22 Y. Wang, Q. He, J. Guo, H. Wei, K. Ding, H. Lin, S. Bhana, X. Huang, Z. Luo, T. D. Shen, S. Wei and Z. Guo, ChemElectroChem, 2015, 2, 559.

23 Y. Wang, J. Clancey, G. Lu, J. Liu, L. Liu, J. Chaudhuri, S. George, M. Xie, S. Wei and Z. Guo, J. Electrochem. Soc., 2016, 163, F1.

24 D. Xu, Z. Liu, H. Yang, Q. Liu, J. Zhang, J. Fang, S. Zou and K. Sun, Angew. Chem., Int. Ed., 2009, 48, 4217.

25 K. Wang, R. Sriphathoorat, S. Luo, M. Tang, H. Du and P. K. Shen, J. Mater. Chem. A, 2016, 4, 13425.

26 A. K. Shukla, A. S. Aricò, K. M. El-Khatib, H. Kim, P. L. Antonucci and V. Antonucci, Appl. Surf. Sci., 1999, 137, 20.

27 J. Gu, N. Li, L. Tian, Z. Lv and Q. Zhang, RSC Adv., 2015, 5, 36334.

28 J. Gu, C. Liang, J. Dang, W. Dong and Q. Zhang, RSC Adv., 2016, 6, 35809. 